\title{
$-0,1 \mathrm{C}=$ \\ USAMRICD-TR-14-06 \\ MMB-4 Inhibition of Acetylcholinesterase Is Similar across Species
}

\author{
Shane A. Kasten \\ Karen Brecht \\ Michael V. Boeri \\ Catherine A. Hofstetter \\ Joshua Mannion \\ Douglas M. Cerasoli
}

November 2014

Approved for public release; distribution unlimited

US Army Medical Research Institute of Chemical Defense 3100 Ricketts Point Road Aberdeen Proving Ground, MD 21010-5400

an element of the US Army Medical Research and Materiel Command 


\section{DISPOSITION INSTRUCTIONS:}

Destroy this report when no longer needed. Do not return to the originator.

\section{DISCLAIMERS:}

The views expressed in this technical report are those of the author(s) and do not reflect the official policy of the Department of Army, Department of Defense, or the U.S. Government.

The use of trade names does not constitute an official endorsement or approval of the use of such commercial hardware or software. This document may not be cited for purposes of advertisement. 


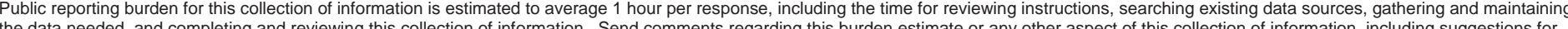
this burden estimate or any other aspect of this collection of in

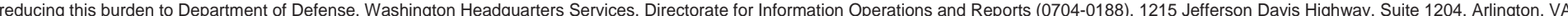

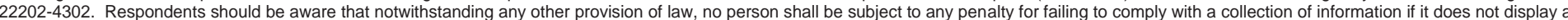
currently valid OMB control number. PLEASE DO NOT RETURN YOUR FORM TO THE ABOVE ADDRESS

\section{REPORT DATE (DD-MM-YYYY) \\ November 2014}

4. TITLE AND SUBTITLE

MMB-4 Inhibition of Acetylcholinesterase Is Similar across Species
3. DATES COVERED (From - To)

June 2013 to July 2014

5a. CONTRACT NUMBER

5b. GRANT NUMBER

5c. PROGRAM ELEMENT NUMBER

6. AUTHOR(S)

Kasten, SA, Brecht, K, Boeri, MV, Hofstetter, CA, Mannion, J, Cerasoli, D.

\section{5d. PROJECT NUMBER}

5e. TASK NUMBER

5f. WORK UNIT NUMBER

8. PERFORMING ORGANIZATION REPORT NUMBER

USAMRICD-TR-14-06
Aberdeen Proving Ground, MD

21010-5400

Chemical Defense

ATTN: MCMR-CDR-I

3100 Ricketts Point Road

9. SPONSORING I MONITORING AGENCY NAME(S) AND ADDRESS(ES)

Joint Project Manager Medical

Countermeasure Systems

1564 Freedman Dr.

Ft. Detrick, MD 21702

11. SPONSOR/MONITOR'S REPORT NUMBER(S)

\section{DISTRIBUTION / AVAILABILITY STATEMENT}

Approved for public release; distribution is unlimited.

\section{SUPPLEMENTARY NOTES}

\section{ABSTRACT}

MMB-4, an oxime that can reactivate acetylcholinesterase (AChE) after inhibition by some nerve agents, is currently in advanced development for potential human use as a replacement for the currently fielded oxime 2-PAM. It has long been known that while certain oximes can be therapeutically effective against OP intoxication at appropriate doses, they can also act as reversible inhibitors of AChE at higher doses. This study was designed to test the hypothesis that the unexpected toxicity of MMB-4 in rabbits is due to increased sensitivity of rabbit AChE to inhibition by MMB-4 compared with AChE from other species.

15. SUBJECT TERMS

Acetylcholinesterase, MMB4, reactivation, inhibition, cross-species

16. SECURITY CLASSIFICATION OF:

\begin{tabular}{l|l|l|}
\hline a. REPORT & b. ABSTRACT & c. THIS PAGE \\
UNCLASSIFIED & UNCLASSIFIED & UNCLASSIFIED
\end{tabular}

17. LIMITATION
OF ABSTRACT

UNLIMITED
18. NUMBER OF PAGES

10 19a. NAME OF RESPONSIBLE PERSON Douglas M. Cerasoli

19b. TELEPHONE NUMBER (include area code) 410-436-1338 


\section{Introduction/Overview}

MMB-4, an oxime that can reactivate acetylcholinesterase (AChE) after inhibition by some nerve agents, is currently in advanced development for potential human use as a replacement for the currently fielded oxime 2-PAM. It has long been known that while certain oximes can be therapeutically effective against OP intoxication at appropriate doses, they can also act as reversible inhibitors of $A C h E$ at higher doses. This study was designed to test the hypothesis that the unexpected toxicity of MMB-4 in rabbits is due to increased sensitivity of rabbit AChE to inhibition by MMB-4 compared with AChE from other species.

We measured AChE activity from red blood cell (RBC) ghosts generated from rabbit, guinea pig, monkey, human and rat whole blood. The concentration of MMB-4 that resulted in $50 \%$ inhibition of AChE activity $\left(\mathrm{IC}_{50}\right)$ for RBC ghosts from each species was found to be very similar, differing by roughly two-fold; of note, rabbit AChE was the least sensitive to MMB-4-mediated inhibition. When examined for the capacity to regain activity after inhibition by MMB-4, inhibited rabbit AChE was found to fully reactivate within 20 seconds of dilution of the oxime. Together, the results suggest that the unexpected toxicity of MMB-4 in rabbits is not due to highly efficient inhibition of $A C h E$ in rabbits relative to other species.

\section{Materials and Methods}

\section{Reagents}

Acetylthiocholine (ATCh) and 5, 5' dithiobis 2-nitrobenzoic acid (DTNB) were obtained from Sigma-Aldrich (St. Louis, MO). MMB-4 (1,1-methylenebis 4-hydroxyiminomethyl-pyridinium dimethanesulfonate) was obtained from the stock supply available at the USAMRICD.

\section{Biological Samples}

Guinea pig (Hartley; Charles River Laboratories, Wilmington, MA) and rat (Sprague Dawley, Charles River Laboratories) whole blood was collected at the USAMRICD in heparinized vials and immediately stored at $4^{\circ} \mathrm{C}$ until use. Human, monkey (rhesus macaque), and rabbit (New Zealand White) whole blood (heparinized) was purchased from Bioreclamation IVT (Baltimore, $\mathrm{MD}$ ) and stored at $4^{\circ} \mathrm{C}$ until use. No individual patient information was provided for the human samples.

\section{Red Blood Cell Ghost Preparation}

Red blood cell ghosts were prepared from whole blood samples from each animal species using a previously published method (1). In brief, heparinized whole blood stocks (30ml) were centrifuged at $3,000 \times \mathrm{g}$ for 10 minutes at $4^{\circ} \mathrm{C}$, and plasma was decanted from the cell pellet. Cell pellets were re-suspended and washed consecutively with two volumes of ice cold 
phosphate buffer $(0.1 \mathrm{M}, \mathrm{pH} 7.4)$ followed by centrifugation. Packed erythrocytes were then re-suspended and diluted in 20 volumes of hypotonic phosphate buffer ( $6.7 \mathrm{mM}, \mathrm{pH} 7.4)$ to promote hemolysis. Suspended erythrocytes were ultra-centrifuged at 50,000 x g for 30 minutes at $4^{\circ} \mathrm{C}$. Supernatants were removed and pellets were re-suspended in hypotonic phosphate buffer for two additional washing cycles followed by 50,000 x g for 30 minutes at $4^{\circ} \mathrm{C}$. Erythrocyte ghosts were re-suspended in phosphate buffer and then concentrated by centrifugation at $100,000 \times \mathrm{g}$ for 30 minutes at $4^{\circ} \mathrm{C}$. Red blood cell (RBC) ghosts were pooled and diluted to a final volume of $10 \mathrm{ml}$ with ice cold phosphate buffer $(0.1 \mathrm{M}, \mathrm{pH} 7.4)$. Aliquots of the erythrocyte ghosts were stored at $-80^{\circ} \mathrm{C}$ until use.

\section{AChE Inhibition by MMB-4}

AChE activity was measured using $0.2 \mathrm{mM}$ ATCh and $0.5 \mathrm{mM}$ DTNB in $0.1 \mathrm{M}$ phosphate buffer $\left(\mathrm{pH} \mathrm{7.4)}\right.$ at $25^{\circ} \mathrm{C}$, with detection of the hydrolyzed DTNB product TNB determined by measuring absorbance at $435 \mathrm{~nm}$. AChE activity was determined either in the absence or in the presence of MMB-4 (at 50, 25, 12.5, 6.25, 3.12, 1.56, 0.78, 0.39, 0.19, 0.097, 0.048, 0.024, $0.012,0.006,0.003 \mathrm{mM})$. Assays conducted in the presence of MMB-4 were initiated with a mixture of ATCh, DTNB, and MMB-4. Aliquots of RBC ghosts were quickly thawed and diluted with ice cold $0.1 \mathrm{M}$ phosphate buffer ( $\mathrm{pH}$ 7.4). A sufficient concentration of RBC ghosts was added in the absence of MMB-4 to provide a measurable initial velocity (linear response in accumulation of TNB) over a 5-minute reaction period using a SpectraMax Plus (Molecular Devices, Sunnyvale, CA). Initial velocities determined for AChE in the absence of MMB-4 were set at $100 \%$ and used to normalize velocities measured in the presence of MMB-4. Assays were conducted in triplicate using a 96-well format with data acquisition via SoftMax Pro (version 5.4). An IC 50 value was determined for AChE from each animal species by fitting the percent of AChE activity with respect to MMB-4 concentration in GraphPad Prism (version 5) using a nonlinear regression dose-response model for inhibition (normalized response with variable slope).

Assessing the Rate of Recovery of Activity of Rabbit AChE after Inhibition by MMB-4

Rabbit AChE activity (using rabbit red blood cell ghosts) was measured (as above, at 435 $\mathrm{nm}$ ) in the absence or presence of MMB-4 (3 mM) for 2.5 minutes with $0.2 \mathrm{mM}$ ATCh and 0.5 $\mathrm{mM}$ DTNB in $0.1 \mathrm{M}$ phosphate buffer $\left(\mathrm{pH} \mathrm{7.4)}\right.$ at $25^{\circ} \mathrm{C}$. To determine if MMB-4 inhibition of rabbit $A C h E$ is readily reversible, a fraction of each reaction was diluted 4-fold into fresh 0.2 $\mathrm{mM}$ ATCh and $0.5 \mathrm{mM}$ DTNB and reaction rates were monitored for an additional $\sim 2$ minutes. 


\section{Results}

\section{UV/Vis Spectrum of MMB-4 and TNB}

MMB-4 absorbs light maximally at $\sim 400 \mathrm{~nm}$, with significant absorbance at $412 \mathrm{~nm}$ (Figure 1A). TNB, the reaction product of DTNB, has a maximum of absorbance at $412 \mathrm{~nm}$ (Figure 1B). Spectrophotometric assays are typically designed to measure the loss or accumulation of a single chemical species in a reaction system. At $435 \mathrm{~nm}$ the absorbance profile of MMB-4 is significantly depressed (see Figure 1A), while the absorbance of TNB at $435 \mathrm{~nm}$ is only modestly lower than at $412 \mathrm{~nm}$. Therefore, AChE activity and inhibition studies were carried out at 435 $\mathrm{nm}$ to reduce interference from MMB-4.

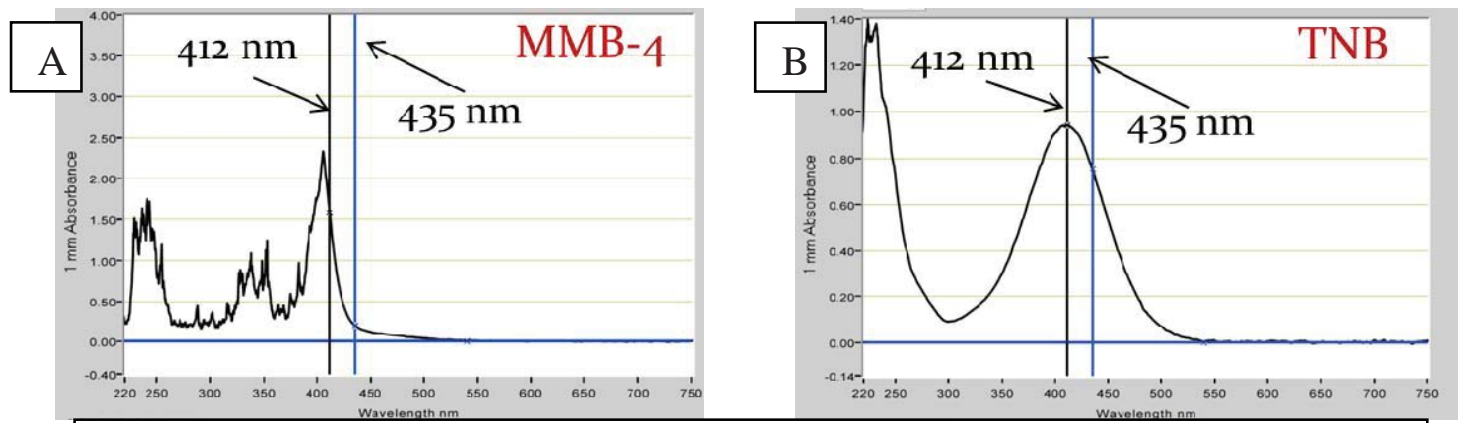

Figure 1. Full spectrum profiles $(220-750 \mathrm{~nm})$ measured for both MMB-4 and TNB. MMB-4 absorbs significantly less at $435 \mathrm{~nm}$ compared to $412 \mathrm{~nm}$. TNB has a maximum absorbance at $412 \mathrm{~nm}$ with $~ 80 \%$ maximal absorbance at $435 \mathrm{~nm}$.

\section{Comparison of $I C_{50}$ Values for MMB-4 with AChE from Different Species}

As shown in Figure 2, MMB-4 was found to be an inhibitor of AChE for each of the species tested, where inhibition ranged from 0 to $100 \%$ over a roughly 2-log MMB-4 concentration range. $\mathrm{IC}_{50}$ values (and associated error) for $\mathrm{MMB}-4$ with each $\mathrm{AChE}$ sample were calculated from these curves, as shown in Table 1 . Note that the lower the $I C_{50}$ value, the stronger the inhibition. The $\mathrm{IC}_{50}$ values were very similar for AChE from each species, differing by roughly 2fold. Rhesus macaque AChE was found to be the most sensitive to inhibition by MMB-4, while rabbit AChE was the least sensitive. 


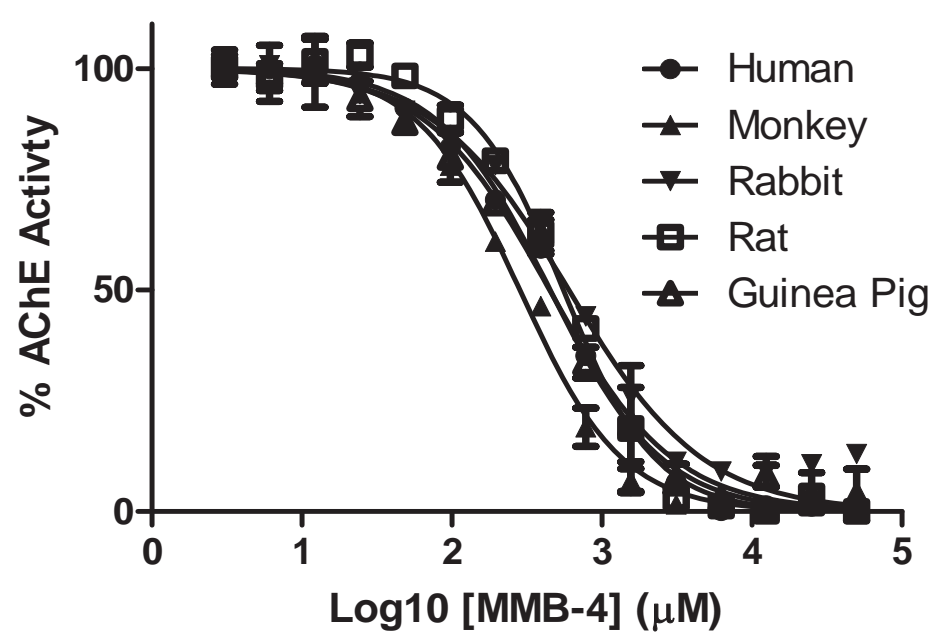

Figure 2. Percent $A C h E$ activity relative to MMB-4 concentration for each animal species. The concentration of MMB-4 that reduces $\mathrm{AChE}$ activity to $50 \%$ is the $\mathrm{IC}_{50}$ value.

Table 1. $\mathrm{IC}_{50}$ values for MMB-4

\begin{tabular}{|l|c|}
\hline Animal Species & IC $_{50}[95 \% \mathrm{Cl}](\mu \mathrm{M})$ \\
\hline Human & $452.5[426.2-480.3]$ \\
\hline Monkey (Rhesus macaque) & $283.9[259.1-311.0]$ \\
\hline Rabbit (New Zealand White) & $600.5[534.4-674.9]$ \\
\hline Guinea Pig (Hartley) & $448.3[380.3-528.4]$ \\
\hline Rat (Sprague Dawley) & $554.4[482.3-637.4]$ \\
\hline
\end{tabular}

Assessing the Capacity of Rabbit AChE to Recover Activity after Inhibition by MMB-4

To determine if MMB-4 inhibition of rabbit AChE is readily reversible, a modified Ellman's assay (2) was used. For these experiments, AChE activity from rabbit RBC ghosts was determined in the presence of MMB-4 at $3 \mathrm{mM}$ (well above the $\mathrm{IC}_{50}$ value). As shown in Figure 2 , this concentration of MMB-4 was sufficient to cause substantial inhibition of AChE activity. If MMB-4 dissociates slowly from the AChE active site, inhibition is expected to persist following dilution of MMB-4. After initial incubation of rabbit AChE with $3 \mathrm{mM} \mathrm{MMB-4,} \mathrm{samples} \mathrm{were}$ diluted 4-fold and immediately assessed for activity. As shown in Figure 3, the inhibition of rabbit AChE by MMB-4 is very rapidly reversed when the oxime is diluted; the activity level of 
MMB-4-inhibited rabbit AChE was indistinguishable from uninhibited rabbit AChE within 20 seconds of dilution of MMB-4.

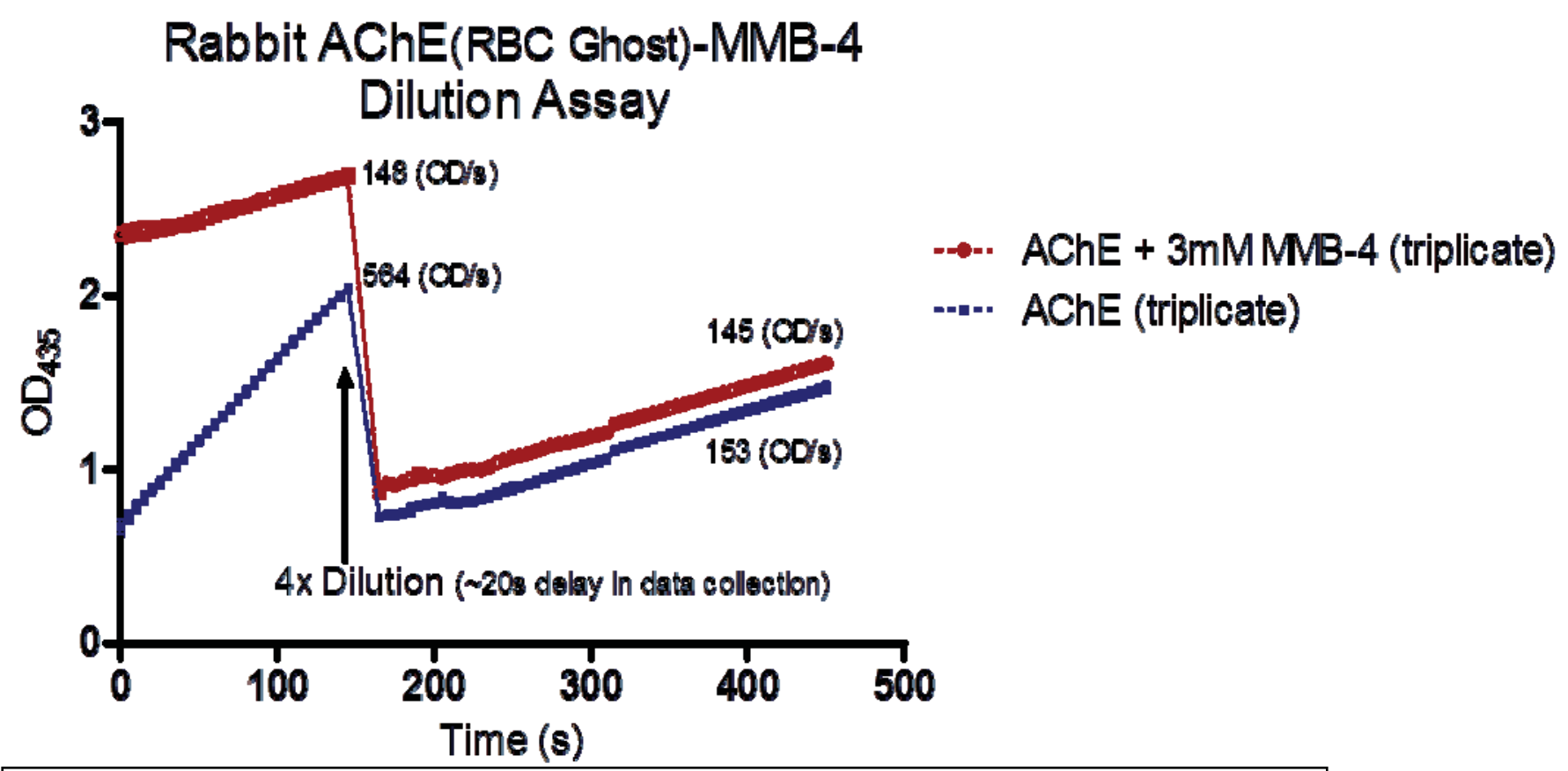

Figure 3. Reversal of Inhibition of Rabbit AChE by MMB-4 after Dilution. AChE activity was measured in the presence ( $3 \mathrm{mM}$ ) and absence of MMB-4 for 120 seconds. After a 4-fold dilution (and 20-second gap in data collection) of the samples, AChE was assessed again. Rabbit AChE activity was restored to uninhibited levels very rapidly following sample dilution (and reduction in MMB-4 concentration).

\section{Discussion}

We examined the capacity of MMB-4 to inhibit AChE activity in RBC ghosts from human, monkey (rhesus macaque), rabbit (New Zealand White), guinea pig (Hartley), and rat (Sprague Dawley). Monkey AChE was the most sensitive to MMB-4 inhibition, with the lowest $\mathrm{IC}_{50}$ value measured ( $284 \mathrm{uM}$ ) for any of the animal species. Rabbit AChE was the least sensitive to inhibition by $\mathrm{MMB}-4$, with an $\mathrm{IC}_{50}$ of $\sim 600 \mathrm{uM}$. This result provides strong evidence to reject the hypothesis that the unexpected toxicity of $\mathrm{MMB}-4$ in rabbits is due to direct inhibition of rabbit AChE by MMB-4.

Even though the $\mathrm{IC}_{50}$ values for $\mathrm{MMB}-4$ were remarkably similar (differing by only 2 -fold) among all species tested, it remained possible that the increased sensitivity of rabbits to MMB4 could be mediated by an extremely slow off-rate of MMB-4 from rabbit AChE; the $\mathrm{IC}_{50}$ values presented were generated in the presence of excess MMB-4, and thus the dissociation rates of MMB-4 from the enzymes could not be determined in these experiments. We examined the 
rate of recovery of rabbit AChE activity after inhibition by MMB-4 and subsequent dilution to reduce the MMB- 4 concentration. The results indicate that rabbit $A C h E$ recovers activity very rapidly (within 20 seconds) after reduction in MMB-4 concentration, providing further evidence to reject the hypothesis that differential sensitivity of the rabbit to MMB-4 toxicity is mediated by interaction with AChE.

Together, the data suggest that the enhanced sensitivity of rabbits to MMB-4 is not due to inhibition of AChE, but rather has origins in an alternate mechanism of toxicity. 


\section{References}

1. Worek, F., Reiter, G., Eyer, P., and Szinicz, L. (2002) Reactivation kinetics of acetylcholinesterase from different species inhibited by highly toxic organophosphates, Arch Toxicol 76, 523-529.

2. Ellman, G. L., Courtney, K. D., Andres, V., Jr., and Feather-Stone, R. M. (1961) A new and rapid colorimetric determination of acetylcholinesterase activity, Biochem Pharmacol 7, 88-95. 